\title{
0613 HOW TO PREVENT DOG BITE INJURIES? THE BLUE DOG
}

K Meints*, T De Keuster, R Butcher Correspondence: University of Lincoln, Brayford Pool LN67TS, UK

\subsection{6/ip.2010.029215.613}

We carried out an empirical assessment of children's learning success using the interactive dog bite prevention $\mathrm{CD}$ 'the blue dog'. In a cross-sectional experimental design, ninety-six 3-, 4-, 5- and 6-year-old children saw eight different child-dogscenes with or without verbal feedback. In the initial exposure phase children chose an outcome after $4 \mathrm{~s}$. The clip then continued for another $6 \mathrm{~s}$. In the training phase scenes were shown again, but now children saw all outcomes, unsafe and safe. In the testing phase different cartoon actors and dogs were used for the same scenes, interspersed with eight distracter scenes. Children again chose the outcome. Children were re-tested after 2 weeks. Half the children received additional parental input before the re-test. A repeated-measures analysis of variance was carried out with age, verbal feedback and parental support as independent variables and the chosen outcomes in the test phases as dependent variable. Results show significant increases in correct responses after using the $\mathrm{CD}$ in all 


\section{IP Safety 2010 abstracts}

children. Children retained this knowledge after 2 weeks. As expected, older children exhibit more correct responses than younger children. Children who received additional parental input performed better than others, with children under 6 years profiting most from parental input. Assessment results indicate that children learn successfully from the 'test yourself' module on the $\mathrm{CD}$. Therefore, the $\mathrm{CD}$ helps to educate children to behave safely with dogs and helps reduce dog bite incidents in children. 